\title{
Some Comments on the Lakoffean Conception of Spatial Imagery
}

The following comments grew out from two accidental encounters I had in one week with approaches to literature that involve the cognitive-linguistics oriented work developed by Lakoff, Johnson, Turner, Fauconnier and others. Significantly enough, in both instances I faced groups of scholars who presumed to speak in the name of "Literature and Cognitive Science", while handling merely a small area of the field. A spokesman for one of the groups made a few very intelligent and penetrating comments from the point of view of the Lakoff approach on my paper "Aspects of Cognitive Poetics", among them the following:

Your paper implies criticism of their work at several points: their redefinition of metaphor as a conceptual rather than a linguistic function, their in-attention to the affective responses elicited by poetry, and their preoccupation with spatial imagery, among others.

Since that paper opens only a small window into my work, I thought I'd better clarify two points with reference to these comments concerning the "redefinition of metaphor", and the "preoccupation with spatial imagery". Parts of this analysis were written for this specific answer; but considerable parts were just copied and pasted with the necessary changes from earlier publications of mine.

\section{Metaphor-Verbal or Conceptual?}

As for "their redefinition of metaphor as a conceptual rather than a linguistic function", I have never adopted an either/or position in this respect. Metaphor has two facets: a linguistic one, and one that concerns world knowledge (which, 
in turn, is represented in the mind as a system of concepts). Howard Gardner (1982) found convincing empirical evidence that these two facets are related to different brain centres, located in the left and the right hemispheres. My position in this respect can best be epitomised through my criticism of the following assertion by Margaret Freeman (in press): "Cognitive poetics may be characterized, as I noted at the beginning, by its recognition that meaning does not so much reside in language as that it is accessed by it. We as speakers /readers bring to our understanding of an utterance/text our world knowledge, which includes cultural knowledge, socio-political-economic knowledge, and so forth". This, of course, is no way to characterise cognitive poetics as I conceive of it. It is a half truth combined with a platitude. As for the second sentence, it is a platitude. It is difficult to find a single approach to poetry that thinks otherwise. As for the first sentence it conveys a half truth. If it is true, then it makes little difference whether we say "birds" or "feathery flocks". The fact that we find them interchangeable suggests that we are using world knowledge. The fact that one poetic style would prefer the former, another style the latter suggests that it is important what words are used. The logic in "redefining metaphor as a conceptual rather than a linguistic function" should be made to work in both directions. The fact that a wide range of verbally different metaphors can be reduced to a single "basic" metaphor suggests that they have some common conceptual foundation; the fact that they are verbally so different, may be of great stylistic — eventually, literaryinterest. I am not critical of "their redefinition of metaphor as a conceptual function"; I am critical of their excessive preoccupation with the reductive possibilities of metaphors rather than with their stylistic uniqueness. Let me put it differently. According to Jakobson, there is a hierarchy of signs: a string of graphemes that signify a string of phonemes that signify a string of units of meaning, and so forth, until extra-linguistic reality is signified. Since we all communicate about extra-linguistic reality, in the everyday use of language we go as fast as possible all along this hierarchy of signs. This would be in harmony with the statement that "meaning does not so much reside in language as that it is accessed by it". However, the differentia of poetic language is, according to Jakobson, that it delays attention at the earlier strings of signs (for instance, by saying "feathery flocks" rather than "birds", our attention lingers both on semantic units and on sound patterns, that is, on language, before reaching world knowledge).

I don't really know what does it mean "meaning does not so much reside in language as that it is accessed by it"; but I may try briefly to explore it. In fact, the question appears to me very much like the question whether the zebra has white strips on a black background, or black strips on a white background. Are words phonological clusters to which concepts have been assigned, or concepts to which phonological clusters have been assigned? A word's meaning is 
a relationship between a phonological cluster and a concept. As long as words and syntax) are language, meaning is language too. Now meaning should be kept apart from reference. Consider, for instance, the following two phrases: The President who plays the saxophone", and "The President who is said to have had an affair with Monica Lewinsky". These two phrases have very different meanings; the realisation of this requires linguistic knowledge. But the two phrases may have the same referent; the realisation of this requires the realisation of a relationship between language and extra-linguistic reality. If I am right, reference can be accessed through language (including meaning). And if it adopts Jakobson's position (as I think it should), cognitive poetics may be characterized by its recognition that meaning patterns and sound patterns (in short, linguistic patterns) are assigned greater significance in the poetic use than in the nonpoetic use of language, in accessing extra-linguistic referents.

\section{God's Will and the Primary Process Hypothesis}

Nor do I criticize the cognitive linguists "preoccupation with spatial imagery". I don't think they ought not to be preoccupied with it but, rather, that they ought to be preoccupied with it in a different way. I think their preoccupation is insufficient to some extent. I will propose here four hypotheses as explanations for the use of spatial imagery in thinking and in figurative language, and will consider their relative merits as explanations: primary process, embodied mind, efficient coding, and attempts to cope with certain limitations of the human cognitive system. In addition, I will reconsider Lakoffs notion of mediated associations ("grounding"). Finally, I will attempt to draw together all the considerations in this paper in one example originally propounded elsewhere, for a different purpose.

The most obvious reason for using spatial imagery in metaphors is that the language of the primary processes (e.g., dreams) is spatial imagery. This can explain everything, but is trivial: it is always true, and you cannot make meaningful distinctions with it in a text or in changing contexts. Being "always true" brings us face to face with the Occamian principle that "entities should not be multiplied beyond necessity", and suggests a kind of relationship, of which the God-Nature relationship is an archetypal instance. Kenneth Burke shows how "the monotheistic concept of an all-inclusive God was itself an ambiguous preparation for naturalism” (Burke, 1962: 80).

For if nature was deemed, as it was by many of the devout, to be a perfect exemplification of God's will, then nature's design would accurately represent the design of God. Hence, reference to God as the locus of motives would involve an unnecessary duplication of terms (Burke, 1962: 80). 
Likewise, pointing out that spatial imagery in language is effective because it is a perfect exemplification of the spatial imagery of primary processes would lead us nowhere: it would merely involve an unnecessary duplication of terms. Burke further observes that "this naturalistic side of the equation had the further advantage of opening the way to experiment" (Burke, 1962: 81). One of the reasons for Freud's enormous success in the interpretation of dreams is that he never fell back on the explanation "because the language of the primary process is essentially spatial visual imagery"; this opened the way to the subtle observation of the changing meanings of the spatial images in changing contexts.

\section{The Embodied Mind Hypothesis}

A less ubiquitous explanation is the embodied mind hypothesis. This involves the claim that all thinking originates in bodily experience. A range of schemata formed during our early experience manipulating a physical world of surfaces, distances, and forces, lays the foundation of later, more abstract modes of thought. Consider, for instance: "The idea is that balance is something that we learned with our bodies and not by grasping a set of rules [...] And the point here is that it's not just an arbitrary thing, that we happen to use balance in talking about these other kinds of things" (Gibbs. 1997). This conception is intuitively very correct, and one thing is certain: the bodily sensation, where relevant, can reinforce the effectiveness of spatial imagery. But, again, it is rather poor when it comes to explain the difference between such expressions as "balanced personality", "balanced judgment", "out of balance", or "balance sheets".

When Ray Gibbs derives Hamlet's wavering "to be or not to be" and "Whether 'tis nobler in the mind to suffer ... Or to take arms against a sea of troubles" too from the elementary physical sensation of loss of balance, we reach a point when anything can be derived from anything, and the whole conception becomes trivial. Just as natural scientists are to be judged according to their experimental results' and empirical measurements' ability to define the differences between the various natural phenomena rather than their ability to point out that these phenomena are all appropriate expressions of God's will, a rational discipline of poetics should be judged according to its ability to make meaningful stylistic distinctions between, e.g., the phrase "balance sheets" and Hamlet's soliloquy. To be sure, one cannot make meaningful distinctions without having sufficient common grounds. My point is that in this case the elementary sensations of physical balance are not such sufficient common grounds, just as God's will is not sufficient common grounds for comparing the various natural phenomena. 


\section{The Clerk's Tale and the Metaphysical Conceit}

David Miall in his excellent review of Mark Johnson's book The Body in the Mind (1987) refers to one of Johnson's discussions. In Chapter 1 Johnson begins his detailed analysis of their presence by examining the schemata underlying a specific passage, taken from the report of a legal clerk discussing his response to a certain type of woman. The passage provides important insights into the impulses that may result in rape. The clerk's account reads in part as follows:

Let's say I see a woman and she looks really pretty, and really clean and sexy, and she's giving off very feminine, sexy vibes. I think "Wow, I would love to make love to her," but I know she's not really interested. It's a tease. A lot of times a woman knows that she's looking really good and she'll use that and flaunt it, and it makes me feel like she's laughing at me and I feel degraded. I also feel dehumanized, because when I'm being teased I just turn off.

The clerk then reflects on the double bind this imposes on him, and comments: "Just the fact that they can come up to me and just melt me and make me feel like a dummy makes me want revenge" (6: cited from Beneke, 1982).

Johnson's discussion of the underlying logic of the passage is illuminating. As he points out, the dominant idea motivating the clerk's understanding of his response turns out to be metaphoric: Johnson states this as "PHYSICAL APPEARANCE IS A PHYSICAL FORCE." Johnson shows how this metaphor, and derivatives from it, shape the clerk's discourse. One implication of the clerk's account is the notion that "ANYONE USING A FORCE IS RESPONSIBLE FOR THE EFFECTS OF THAT FORCE" (8). This and other hidden assumptions of his response propel the clerk towards a violent construal of his predicament. Either it requires an act of violence towards himself, suppressing his feelings of sexual desire, resentment, and humiliation — which is the path he actually seems to adopt—or it requires a sexual assault upon the offending woman.

Now Johnson seems to overlook a small difference between the clerk's response and the "metaphoric path". For the clerk this is not a mere way of speaking; he actually experiences the physical appearance of the female body as something that exerts some physical force on him. I will return later to this issue. Miall, in his own way, seems to agree with my assessment. In what follows, he is "concerned to show in particular that the urgency of the clerk's predicament springs from a level more fundamental than the metaphor described by Johnson". .Anyway, Miall's discussion would suggest that several theoreticians feel that something important is missing from Johnson's account. 
Another dimension of such feelings is apparent in the clerk's use of the term "really clean and sexy." While the narrative is obviously about bodily experience, one important construction not noted by Johnson involves the construct "clean vs. defiled." The clerk's idea of intercourse includes, among other matters, the prospect of degrading the woman's purity. Being physically degraded himself calls for despoiling her physically in revenge. As Ricoeur (1969) has pointed out, the sense of defilement is itself figurative, being based on the literal meaning "stain" or "unclean." But more important, defilement evokes a sense of dread: dread "of a danger which is itself ethical and which, at a higher level of the consciousness of evil, will be the danger of not being able to love any more, the danger of being a dead man in the realm of ends." With such dread, Ricoeur notes, comes the "primordial connection of vengeance with defilement" (Ricoeur, 1969, 15, 30).

Likewise, “Johnson's analysis of the clerk's narrative has been criticized for overlooking the gender issues it raises (Hayles, 1993)". All this reminds me of Jakobson's comment on some literary critics who behave similarly to the district policeman in Zarist Russia: he was sent to arrest a certain culprit; if he didn't find him, he arrested all his neighbours. Let us remind ourselves: we are speaking of metaphoric structures; Miall (quoting Ricoeur) and Hayles are speaking of rather remote neighbours. So, who is the real culprit? John Crowe Ransom's discussion of the Metaphysical Conceit may give us a substantial clue. Ransom speaks of the principle of "miraculism" this rule is at work, he says, "when the poet discovers by analogy [or contiguity-R. T.] an identity between objects which is partial, though it should be considerable, and proceeds to an identification which is complete" (Ransom, 1951: 786). In other words, the Conceit is a metaphor [or metonymy - R. T.] that is "developed so literally that it must be meant" (ibid., 784). Now, the clerk, too, discovers a partial (though substantial) identity between "PHYSICAL APPEARANCE" and "PHYSICAL FORCE", and proceeds to an identification which is complete. The identity is partial, because the statement "ANYONE USING A FORCE IS RESPONSIBLE FOR THE EFFECTS OF THAT FORCE" applies to physical forces, but not to physical appearance. The culprit, then, is this: the clerk discovers an identity that is partial, and proceeds to an identification which is complete.

Notwithstanding, what the clerk does would hardly count as a Metaphysical Conceit. In order to understand how, according to Ransom, metaphysical conceits work in poetry, I will reproduce here a longish section from an earlier book of mine (Tsur, 1992b: 376378). Let us begin our discussion with Abraham Cowley's 'ingenious' conceit of exchange of hearts in "The Change":

Oh take my Heart, and by that means you'll prove Within, too stor'd enough of love: 
Give me but yours, I'll by that change so thrive

That love in all my parts shall live.

So powerful is this change, it render can My

outside Woman, and your inside Man.

Ransom (1951: 784) quotes this stanza as containing a notorious example of the metaphysical conceit. "A conceit originates in a metaphor; and in fact the conceit is but a metaphor if the metaphor is meant: that is, if it is developed so baldly that nothing else can be meant". And further on he says, "such is Metaphysical Poetry; the extension of a rhetorical device" (ibid., 786).

Admittedly, Cowley is not the first poet to substitute heart for affection (cf. Sidney's "My true love hath my heart and I have his"). The startling quality of this image seems to be due to the fact that this metonymic device is developed so literally that this meaning must be intended. In this way, Cowley succeeds "in depositing with us the image of a very powerful affection" (Ransom, ibid.). Yet, contrary to common belief neither this way of handling imagery nor this particular image is the exclusive invention of seventeenth century metaphysical poets. Consider, for instance, two centuries earlier, Villon's Rondeau on the death of his mistress:

Deux e'tions et n'avions qu'ung cuer;

S'il est mort, force est que devie,

Voire, ou que je vive sans vie

Comme les images, par cuer,

Mort!

The heart is traditionally considered as the seat of thought, feeling or emotion, and Villon, like Cowley, develops the "miraculous" element in his image in two steps: first, by a metonymic transfer from "affection" to heart, and then, by developing this device so literally that it must be meant. The idea that the two lovers were inseparably united by a single affection is expressed as "we were two, and had only one heart", which appears to be miraculous enough, if you conceive of the heart as of a hollow muscular organ, of which you know that there must be one and only one in every human body. That is, by a logical development of those aspects of "heart" that are irrelevant to "affection", Villon achieved a miraculous, or witty, effect. The image is, then, further developed, and "too" literally: since she died with the only heart we had, I have been left without a heart. The image thus developed may suggest further metaphoric or metonymic implications (based on the fact that the heart is traditionally considered as the seat of life or vital powers): since there is no life without a heart, my life is in fact no life: and since there is no body without a heart, my body is no body any more, but a mere lifeless image. Notice also that although the physiological 
aspects of the heart image have been developed according to a consistent logic, the various figurative implications of the image need not be logically consistent with one another.

Now there is one crucial difference between what the clerk does and what Cowley and Villon do. The latter (as well as their readers) know perfectly well that they are dealing with a logical fallacy, treating a partial identity as a complete identification, for an aesthetic purpose: to achieve certain aesthetic affects; and that this requires the willing suspension of disbelief. The clerk, by contrast, does believe in the complete identification. For him, the complete identification is not a source of some playful aesthetic effects, but rather of some earnestly threatening forces.

According to Miall, the specific metaphor the clerk deploys is a construct available from the culture. "If the clerk's discourse is examined as an example of the structuring of conventional meaning, it is so primarily because the metaphor for which he reaches is a cultural commonplace". For Johnson, a range of schemata formed during our early experience manipulating a physical world of surfaces, distances, and forces, lays the foundation of later, more abstract modes of thought. I have a vested theoretical interest that both should be right. Cognitive poetics, as I conceive of it, assumes that cultural conventions originate in some live cognitive processes, to which some fossilizing defence mechanisms were applied. But for our present purposes, this makes precious little difference. What we are dealing with is the culprit: treating a partial identity as complete identification. In poetry, at least, this yields two different researches. One of them studies the cognitive origins of cultural conventions; the other one explores the effects of treating a partial identity (derived from cultural convention or directly generated from live cognitive processes) as a complete identity. If they are derived from cultural convention, their cognitive origins are irrelevant to the second kind of research. Falling back on "PHYSICAL APPEARANCE IS A PHYSICAL FORCE" instead on "treating a partial identity as a complete identity" as an explanation will block rather than promote understanding. With psychotic or mentally disturbed people further complications may be involved, since they don't necessarily realise that the complete identification is a fiction.

The body-in-the-mind hypothesis is all too frequently used in a reductionist manner, disregarding significant differences. In the present section we have distinguished between three kinds of possibility. 1. One may discover a partial identity between a physical image and some mental process, generating in poetry some metonymic or metaphoric transfer (as in Sidney's verse above). 2. One may treat this partial identity as a complete identity, in order to generate certain aesthetic effects (as in Cowley's and Villon's verse above). Such a use crucially depends on the willing suspension of disbelief, on an awareness that one merely pretends to take the complete identification literally. This makes the crucial 
difference between the poet and the psychotic. 3. One may believe (as the clerk seems to believe) that the complete identification is literally true. The body-in- the-mind hypothesis has very important things to offer to the cognitive study of language and of the mind. But as long as it is treated as a wholesale, unqualified truth, the results of its application will be problematic.

Miall too criticizes Johnson for treating all spatial foundations of more abstract relationships as if they were of one kind. He insists on

an important psychological distinction between an instantiation of semantic meaning and an awareness of semantic change; or, to put it differently, a distinction between familiar meaning and the defamiliarization of meaning that occurs most notably in literary texts. For example, the spatial implications of "rear" or "front" are common in everyday discourse. We no longer notice their figurative origin in such uses as "She was at the front of her class in math"; "He kept at the rear in conversion". If these uses are metaphoric, as Johnson would claim, they have become domesticated, dead metaphors. The process of comprehension clearly differs when the words are used in a context such as this poem by Emily Dickinson: "Remembrance has a Rear and Front - / 'Tis something like a House (Dickinson, 1970, 524).

I agree with every word of Miall's in this paragraph; and will have later further comments on this issue of "defamiliarization".

A sympathetic reader of the present paper made, nevertheless, the following critical comment.

Does not Miall's argument (and your following him) come down to this? You've talked about X, but you didn't mention Y, Z, A, B ... I have to say that I find this comment by reviewers particularly irksome. After all the author wrote the paper he/ she wrote, not some other. More could be said about any topic you care to name.

This comment is most disconcerting for me, because I too find that practice of reviewers particularly irksome and I too believe that the author is sovereign to decide what he ought to write about. Notwithstanding, I believe we are in an academic discipline, and that certain principles and constraints on our work ought not to be disregarded. This problem becomes particularly acute when we pursue interdisciplinary research and, first and foremost, the application of linguistic, cognitive or neurological hypotheses to literature. Here the dangers of reductionism are lurking all the time.

Let me offer a rudimentary answer to the above criticism. What David Miall in his insistance on "a distinction between familiar meaning and the defamiliarization of meaning") and myself say, in fact, to Mark Johnson (and many other scholars in that research tradition) is this: What you say about the Mind-in-the-Body hypothesis is very important. But you should be aware of the constraints on its application. There is an insidious danger of "unnecessary 
duplication of terms", as Kenneth Burke put it. In applying the hypothesis to poetry (or to the clerk's tale, for that matter), one should avoid offering a true description in the Mindin-the-Body language, if it is not used to make significant distinctions within or between texts. There are ten thousand different ways to do that. We are offering our readings not as an imperative "You should have done this!", but as examples of how this could be done.

\section{The Efficient Coding Hypothesis}

The third hypothesis conceives of concrete objects and spatial images as bundles of features "grown together". According to Neisser (1968: 320), "the amount of information may require less capacity coded in terms of spatial relationships than in terms of temporal sequence. [...] This assumption would explain the predominance of visual imagery in dreams, and perhaps also our preference for visual models and metaphors for thinking, from 'insight' to 'point of view' " Each feature indicates some meaning potential that may be realized in certain contexts. This can explain why some spatial image changes its meaning when it enters into different contexts, or when the context is continually changing. This can also explain, why human understanders can move with amazing ease from one potential meaning of an image to another. Likewise, it can explain why creative thinking is based on spatial imagery rather than on verbal coding: it saves mental processing space (much information is coded into a single image), and grants the user enormous flexibility in moving from one meaning potential to another. As J. J. C. Smart (1966) has convincingly shown, the productivity of visual models in scientific research is sometimes based on this property of physical objects, in combination with the principle of treating a partial identity as a more complete identity. You may, for instance, establish a partial identity between gas particles and a swarm of billiard balls: and then discover that certain features of billiard balls, that have been regarded as irrelevant to this identification, may suggest new, productive ideas about the behaviour of gas particles, thus rendering the identity more complete.

This has some far-reaching aesthetic implications too. A single image encoding a variety of meaning units can be regarded as an instance of the aesthetic principle "unityin-variety". This also can be said to save considerable mental energy, and as Kris and Gombrich (1961) pointed out following Freud, one possible source of pleasure is the saving of mental energy. Or, to paraphrase Charles Peirce's and Umberto Eco's semiotic discussion of "abduction", such a coding substitutes a single predicate for a complicated tangle of predicates, replacing a complicated feeling "by a single feeling of greater intensity" (Eco, 1979: 132). Compare, for instance, "the roses of her cheeks" with "the pinkness, 
softness, and beauty of her cheeks". Such a conception enables the practical critic to compare the use of one image in different contexts not only in terms of the specific meaning potentials realized, but also in terms of the number of meaning potentials realized, or compare the same predicates when spelled out one by one or encoded in one single spatial image. This, in turn, may have some implications for evaluation. This also allows the speaker to say "the roses of her cheeks-I don't mean their pinkness, softness, or beauty, but their thorns".

\section{The Hypothesis of Overcoming Cognitive Limitations}

The fourth hypothesis requires a rather long discussion. Having recourse to, or moving away from, spatial visual imagery serves usually attempts to cope with certain limitations of the human cognitive system. For present purposes, stable, characteristic visual shapes display spatio-temporal continuity and a relatively high degree of differentiation. One kind of limitation of the cognitive system consists in the fact that certain undifferentiated, rapidly changing information cannot be reliably treated unless it is recoded into a template of stable, characteristic visual shapes. This, however, is done at the price of losing some vital sensory information. An opposite kind of limitation we find in the stability of the conceptual system reflected in language. When we speak of insight, emotion, mystic experience, altered states of consciousness etc., we speak of elusive, lowly-differentiated states of mind, that escape the tyranny of our conceptual system. Language, however, can label only highly differentiated, stable concepts. Since poetry is written in language, "mystical poetry", for instance, ought to be a contradiction in terms. We know this is not the case. Cognitive poetics, as I conceive of it, explores, among other things, the ways of poetry to escape from the tyranny of conceptual thinking. The organisation of elusive, fluid, lowly differentiated experiences into a spatial template may increase their stability and differentiation. Resorting to'shape-free qualities and speaking of the more differentiated senses in terms of the less differentiated senses arouses a feeling that the experiences presented are more elusive, less stable and less differentiated than the concepts denoted by the words used to describe the experiences. The following paragraphs are extracted with the necessary changes from the chapter "Some Spatial and Tactile Metaphors for Sound" in my What Makes Sound Patterns Expresive-The Poetic Mode of Speech Perception (1992a).

In his work on "Panchronistic Tendencies in Synaesthesia", Ullmann (1957) discovered an overwhelming tendency in Romantic and Post-Romantic poetry of several languages to perform metaphoric transfer in a direction from the more lowly differentiated sense to the more highly differentiated one. Keats's famous line 


\section{And taste the music of this vision pale}

would be a highly typical instance of this tendency. Here, vision pale belongs to the visual sense, but involves no stable, characteristic visual shape; and is treated in terms of music from the less stable, less differentiated auditory sense which, in turn, is treated in terms of taste, which is still less differentiated. Vision, in distinction from sight, refers not only to the thing seen, but also to an impassioned state of mind with uncanny connotations. The paleness of the vision may be associated with the paleness of the dead, or of Isabella, or of the moonlit sight. This uncertainty may contribute to an indistinct, diffuse quality of the presentation. Music connotes a pleasant fusion of sounds, expanding toward the perceiving self; the transfer to a lower sense, taste, enhances the indistinctness of the fused sensations. The powerful fusion of the discordant senses heightens the discharge of emotions, eliminating the contradictory sensuous ingredients, leaving the reader with the feel of a supersensuous, uncanny atmosphere.

To consider more colloquial, less sophisticated phrases, we might expect to encounter such expressions as warm sounds, soft sounds, heavy sounds, warm colours, soft colours and even heavy colours more frequently than loud temperatures, green temperatures, loud touch, green touch, loud weight, or green weight (Donne's loud perfume was condemned by critics as "the concoction of an experience"). As these examples show, these tendencies are reflected in colloquial expressions as well.

At some variance with Ullmann's explanation, I have elsewhere (Tsur, 1987: 209272) attempted to account for these tendencies. Human language is a highly differentiated, highly conceptualized tool. It seems to be impossible, therefore, to talk about elusive, lowly-differentiated, nonconceptual or noncategorical experiences or streams of information (which appear to be at the very core of poetry, for instance). One way to overcome this limitation is to use synaesthetic metaphor, especially when the transfer proceeds in the "upward direction", that is, when we talk about the more differentiated sense in terms of the less differentiated sense. The visual and auditory domains have extremely rich vocabularies, whereas the other sensory domains are restricted each to a small number of pairs of antonymous adjectives, occasionally with one or two adjectives to mark some intermediate position (e.g., cool and warm between cold and hot). In spite of this, higher sensory domains borrow terms from the lower sensory domains more frequently than is the case the other way around (thus, synaesthetic metaphor is dominated by the "pauper's sheep" principle). Terms of the lower sensory domains are taken to characterize percepts of higher sensory domains (rather than vice versa) whenever we need to characterize some lowly- differentiated perceptual or emotional quality. Apart from its possible semantic 
content, a term of a lower domain transfers to the visual, auditory or emotional experience the feature [-DIFFERENTIATED].

\section{Recoding Auditory Information}

In the aforesaid chapter, I considered at some length the nature of the analogy between sound frequency and spatial vertical direction. Then I further ventured and asked, why do we need this analogy? It is one thing to explain the fact that it is vertical rather than horizontal dimension that is analogous to sound frequency, or it is frequency rather than wavelength that is to be treated as analogous to vertical dimension. And it is another thing to explain the very need for such an analogy.

It seems to me that this analogy serves as a facility for handling noncategorical sensory information. As I quoted Neisser at considerable length in that chapter, sound is a lowly-differentiated, rapidly changing stream of information, consisting of minute stimuli that most accurately signal change. We can discriminate such rich sensory sound information only as long as it reverberates in echoic memory, that is, for a few seconds only. In order to store auditory information for longer periods of time, it must be recoded in some more stable form that is less dependent on the niceties of unique sensory information, and more easily managed by memory. For present purposes, there appear to be two such ways of recoding: categorisation into a phonetic code, and translation into a code of spatial relationships (of a more stable nature).

The first of these codes uses a system of abstract linguistic categories which lend themselves to storing for relatively long periods of time, but at the price of excluding most of the acoustic information. Suppose we ask "What did the man say?", and get the answer "The man said 'ba', or "da", or "ga". We are able to remember these syllables for an hour, or a day, or a month, or even a year; but will be incapable of even noticing the acoustic cues by which these syllables differ from each other. Had we received only the acoustic cues, we could reliably remember them for a few seconds at best. The second of these codes exploits the fact that spatial organization is of a more stable nature than the sequence of sounds, and that it is of central importance in human cognition: it conceives of the relation between sounds as of spatial relationships. Thus, if we cannot remember the exact sensory information about a sound, we still can remember the exact relationship between several sounds, i.e. a scale or melody. The spatial structural template not only enables us to remember relations between sounds, but also enables us a better differentiation between them. The role of the spatial structural template in differentiating sound frequencies will be more readily apparent, if we compare this sound dimension to some other dimension, where 
no such spatial analogue is readily available, say loudness. On this dimension, we can easily differentiate the extremes, and perhaps a few intermediate degrees of loudness. Now, suppose, one hears a single tone of unchanging frequency, with changing degrees of loudness. How many degrees of loudness one will be able to discriminate? And for how long will one be able to remember the sequence of those degrees of loudness? Should we wonder, then, that works of music are primarily composed of sounds of changing frequencies rather than changing amplitudes?

\section{Differentiation}

When the human ear picks up a sound of a certain frequency, its several hundreds or thousands of vibrations per second exceeds its capacity of resolving them; it fuses them into a unitary event categorized as a sound of a certain pitch. Sounds of various pitches are easily differentiable from one another, pitch (frequency) being an indispensable attribute of auditory perception. As we have seen, the most highly differentiated dimension of sound, frequency, is perceived within a structural template of the most highly differentiated dimension of spatial orientation. As I have suggested, the spatial template increases the diferentiation of the sound continuum.

The sensory information of sounds has, however, some less differentiated aspects as well. First and foremost we should mention a highly divergated overtone structure. This overtone structure, too, exceeds by far the resolving power of the human ear. So, its components are fused into a unique and unitary quality, usually called "tone-colour". In Polanyi's terms, one might say that we attend away from overtone structure to tone-colour. Tone-colour differs from one overtone structure to another: tone-colours are fairly discriminable, although they have no category names comparable to visual colours. We usually label tone colours by the name of their characteristic sources, e.g. "wooden", or "metallic" sound. It should not be very surprising that for visual colours we have stable category names, whereas we call sound-colours by the name of their sources. We usually see stable objects with stable properties (and, as Neisser noted not light). But we hear the sound of objects in change or in motion. An experienced listener can make quite fine distinctions; within "metallic colour", for instance, he may discriminate the sound of a trumpet from that of a French horn. The reason for this difference between light and sound appears to be this: light gives us information about stable objects, whereas sound gives us information about change and movement, not about the moving or changing objects.

On a specific level, tone-colours have little in common with visual colour, and it would be odd to talk about "green" or "mauve" sounds. Even when Oscar 
Wilde does use such phrases, they are usually regarded as the extravagancies of a highly idiosyncratic author. At a higher level of abstraction, however, the two kinds of "colour" have certain properties in common. Both are "gestalt-free" qualities, secondary to the "shapes" carried by the "indispensable attributes" of their respective sensory modes. Both may diversely or unify substantial "areas" created by the shapes carried by the respective indispensable attributes. Both have, further, such "tertiary" qualities as "brightness", "dullness", "darkness", and the like. When we apply to sounds such visual terms as colour, brightness and the like, we usually refer to some fairly (but not highly) differentiated qualities whose function is to unify or diversify sound-shapes. By the way, why did I speak of "tone colours" as spread over "areas"? Not only because it brings out the analogy with visual colours. Rather, the stream of sounds is a rapidly changing sequence over time. When speaking of sound shapes, I was interested in certain unchanging relationships between those sounds, abstracted from the sequence. So I tranlsated the temporal sequence of rapidly changing sounds into a spatial template, where most typically unchanging relationships obtain.

\section{Mediated Associations}

Finally, Lakoff raises the all-important question: "is there any reason why conceptual systems contain one set of metaphorical mappings rather than another?"

There are other languages in which MORE IS UP and LESS IS DOWN, but none in which the reverse is true, where more is down and less is up. Why not? The contemporary theory postulates that the MORE IS UP metaphor is grounded in experience - in the common experience of pouring more fluid into a container and seeing the level go up, or adding more things to a pile and seeing the pile get higher. These are thouroughly pervasive experiences; we encounter every day of our lives (Lakoff, 1993: 240).

Lakoff refers to his own view as "contemporary theory". In the afore said chapter I tried to refute attempts to explain instances of intersense analogy with the help of "mediated association". The method consists in directing attention to some very obvious, but still anecdotal, facts, suggesting in one way or other that some classical conditioning takes place, universally, at a very early age in each individuum. Thus, for instance, red is perceived as a "warm" colour, because fire is universally red, while blue is a "cold" colour, because the sea is universally cold. Now all these cannot be contradicted; except the word "because". There are some universal facts that could be appealed to for an opposite association. Thus, for instance, the setting sun is universally red, while the sun at its hottest 
universally appears in a blue sky. Or, consider Lakoff's reference to "the common experience of pouring more fluid into a container and seeing the level go up"; this cannot explain, in anyway, why "MORE FREQUENT VIBRATIONS IS UP". Furthennore, when we look at the DEEP - SHALLOW dimension of the sea, MORE IS DOWN and LESS IS UP-universally. Though this is the exception rather than the rule, it suggests that the old Pavlovian explanation won't do. "Mediated association" should be the last refuge of a cognitive theory. It appears to be of considerable importance, what term we use to denote this notion. When Roger Brown uses the term "mediated association", he directs attention to its origins in behaviourism; when Lakoff calls it "grounding", he directs attention away from them, without changing the facts. I have adapted, in stead, Clark and Clark's cognitive model to the explanation of such analogies.

In describing the succession of sounds, I have used such pairs of antonyms as HIGHLOW, FAST-SLOW, THICK-THIN, WIDE-NARROW. The terms of each pair designate the extremes of one scale, and may be defined as the polar opposite of the other, and can be graded in each other's terms. That which is slower is less fast, and that which is faster is less slow; that which is thinner is less thick, and that which is thicker is less thin, and so forth. Notwithstanding, the two terms of a pair are far from being symmetrical. One term of each pair is relatively unmarked. One may ask, "how long is the movie?", but not "how short is the movie?", when one does not know whether the movie was long or short for a movie. Likewise, one may say "two hours long", but not "two hours short" (cf. Clark and Clark. 1977: 427). Long, in this case, is the unmarked term of the pair, that may designate both the whole scale and one of its extremes. When speaking of antonymous adjectives, one must account not only for such identifications as "more is up", but also for the fact that one term of the antonymous pair is typically used for designating both the whole scale and one of its extremes. This the "mediated association" theory of "grounding" obviously cannot do; we should prefer a structuralist theory of "marking".

If we can account for this asymetry of these pairs of opposite terms, we might also explain why does the "more" extreme of the amount scale correspond to the "up" extreme of the direction scale: or the "high" extreme of the height scale correspond to the "fast" ("high frequency") ex-treme of the frequency scale, and the "low" extreme to the "slow" ("low frequency") extreme, rather than the other way around.

In English, dimensions are described with adjectives like high and low, wide and narrow, far and near, and thick and thin. In each pair the [second] adjective describes lack of extent. But there is an extraordinary consistency among these adjectives. The terms that describe "having extent" are all linguistically unmarked and positive; the terms that describe "lacking extent" are linguistically marked and negative. What 
is even more remarkable is that $[\ldots]$ this is true in all languages [...]. Moreover, children seem to attend more to the objects that "have extent" than to those that "lack extent" and this appears to explain why they typically learn the words for the positive ends of such dimensions first (Clark and Clark, 1977: 533).

And this can, of course, also explain why they tend to use the "unmarked" term to designate the whole scale.

\section{Intersensory Analogies}

The terms that denote "having more" or "consisting of more" are, then, the unmarked and positive ones, whereas the terms that denote "having less" are the marked and negative ones. The rule is that the unmarked ends of the analogous scales correspond to each other: thus, fast vibrations are perceived as "high" tones, slow vibrations as "low" tones.

So, if we experience sounds as low or high, thick or thin, we need not have recourse to "mediated associations" in order to account for this. There appear to be good perceptual reasons for this, deeply rooted in the organization of the human perceptual apparatus. If we realize that sounds of various pitches differ in the width of their vibration (or wavelength), we may assume quite safely that bass voices do share "some intersensony quality with the visual or tactile apprehension of thickness". We need not assume with Roger Brown a mediated association, namely, that people who have bass voices are usually thick. The relationship between the "height" and the frequency of sounds is somewhat more complex but essentially of the same nature: treble voices are felt to be higher than bass voices, because greater height and more frequent vibrations are the unmarked (more salient) extremes of their respective scales, and thus they are matched.

\section{Spatial Orientation}

In the preceding few pages I tried to reassess certain aspects of spatial imagery, those that are frequent preoccupation of Lakoff and his associates. Now I would like to mention a radically different use of space in poetry, on which I have elaborated in a wide range of publications. I am quoting from my paper "Aspects of Cognitive Poetics", just as a short reminder.

In that paper I alluded to brain-research which seems to suggest that language is a predominantly sequential activity, of a conspicuously logical character, typically associated with the left cerebral hemisphere; whereas diffuse emotional 
processes are typically associated with the right cerebral hemisphere. I also mentioned there the problem generated by this state of affairs: while we can name emotions, language does not appear to be well suited to convey their unique diffuse character. I suggested that poets attempt to overcome this problem by creating some verbal equivalent of the structure of emotions. Then I added yet another, highly favoured way of the poets to generate the unique diffuse character of emotions: to evoke in the reader's imagination a landscape in which orientation may take place. The nature of orientation in particular is illustrated by the two hemispheres' different ways of processing input:

The right side of the cortex processes its input more as a "patterned whole", that is, in a more simultaneous manner than does the left. This simultaneous processing is advantageous for the integration of diffuse inputs, such as for orienting oneself in space, when motor, kinesthetic and visual input must be quickly integrated. This mode of information-processing, too, would seem to underlie an "intuitive" rather than "intellectual" integration of complex entities (Ornstein, 1975: 95).

In what I call "delayed categorisation", the phrase "integration of diffuse inputs" undergoes a slight shift of emphasis, from "integration of diffuse inputs" to "integration of diffuse inputs". In the reading of landscape descriptions by way of "delayed categorisation", inputs are perceived as more diffuse.

In the foregoing discussion I tried to scrutinise the spatial notions that are essential for the theory of conceptual metaphor expounded by Lakoff and his associates. I have found that their congitive assumptions were not sophisticated enough for the purposes for which they had been devised, and sometimes they were little more than behaviourism disguised as cognitive science.

I have advanced four hypotheses to account for the tendency to use spatial visual imagery in figurative language and creative thinking. All four suggest very good reasons for having recourse to spatial visual imagery. But there appears to be a difference between them as far as context-sensitivity is concerned. The first hypothesis, that spatial imagery is the language of primary processes, has claims for the same kind of validity whatever the circumstances. Reliance on this principle may result in "an unnecesary duplication of terms", violating Occam's Razor. The second hypothesis, that of the embodied mind, is more flexible: it involves the claim that a "range of schemata formed during our early experience manipulating a physical world of surfaces, distances, and forces, lays the foundation of later, more abstract modes of thought", granting the critic some choice between a range of schemata. This hypothesis, however, too, tends to suggest a relationship that has an a priori nature. It can point out significant processes from which certain conventions arose. But we are dealing with processes that took place, at best, in the distant past of the individual or of the community, and are rarely affected, if at all, by the circumstances in which they are applied. 
We have seen, for instance, that some mental process can be related to some underlying physical image relying on some partial identity; or relying on some partial identity treated as a complete identification while preserving the willing suspension of disbelief; or relying on some partial identity treated as a complete identification while literally believing in the validity of this identification. Failure to distingash between such possibilities may, and does, lead to serious confusion. The other two hypotheses, by contrast, are focused on aspects that require changes in real time, the key word being "functionality": the imagery must be adjusted to purposes defined by the changing context.

\section{Wide, Wide Time}

To couclude this paper, I would like to reproduce here (from Tsur, 1992b: 361- 362) a short discussion, with the necessary changes, of how all the foregoing distinctions and observations converge with respect to a verse line by the great Hebrew poet, Nathan Alterman:

(8) Wide, wide time. The heart rang two thousand.

At first glance, the first phrase of this line may be perceived as a witty play, nothing more. If there is a "long, long time", there may be a "wide, wide time" as well. The Russian formalists and their disciples would perhaps regard this as a brilliant exercise in "making strange", in "deautomatization", in "reviving a dead metaphor". And as such, it is quite effective indeed. The phrase has, however, an intense emotional quality, which cannot be accounted for by the witty alienation device. Some readers feel as if they were wrapt in a low-differentiated texture of "time", or as it were, "plunged" in it; as if the boundaries between self and not- self were suspended, while they (the readers) were "immersed" in "time". Some even report a faint tactile sensation all over the outer surface of their bodies.

The two parts of this verse line present an experience of a time period of very great magnitude. The second part estimates this magnitude conceptually: the imagination selects a unit, which it can then repeat indefinitely. Still, when it is the heart that strikes (as a clock) "two thousand", the description assumes some marked emotional quality. And the two thousand strokes (or beats of the heart) definitely exceed the imagination's power to take it in all at once, even though it can be expressed in numbers, that is, conceptually: the two thousand seats are collapsed into an undifferentiated experience of time. The first phrase, by contrast, suggests the Kantian "aesthetic estimation", in which the imagination tries to comprehend or encompass the whole representation of a time period in one intuition. The apparent size of this period strains this capacity to the limit. 
"Long, long time" would suggest that its size threatens to exceed the imagination's power to take it all in at once. Now, as "long" refers to a spatial dimension, there would seem to be no reason why one should not refer to duration with equal naturalness by the name of another spatial dimension, e.g., "wide". However, as it has been noted, sequential time is a "linear" experience, typically associated with the left hemisphere of the brain. Whenever we refer to only one spatial dimension, we refer to length. As such, the adjective long is felt to be naturally appropriate to a linear use with reference to 'time', even though its original use is for spatial relationships. When wide is substituted for long, we are not dealing with just another spatial dimension, one that might refer equally well to duration. Long refers to that spatial dimension of which there is more; and we tend to associate directionality with it. Wide implies that the space referred to has another, more extensive (in fact, longer) dimension as well, which gives its intuitive direction. Space that extends in all directions into infinity, that is, beyond the horizon, has no length, only width. This is how Coleridge's Ancient Mariner describes infinite space leading nowhere, in which he was hopelessly stuck:

(9) Alone, alone, all, all alone,

Alone on a wide wide sea! (232-3)

It is felt intuitively that one could not change the adjective into "a long long sea". Widh is precisely the spatial dimension that changes the "linear" character of duration into a "patterned whole", having a simultaneous existence or presence. It seems most likely that this involves the heightened activity of the right hemisphere of the brain which is responsible for the diffuuse, low-differentiated quality of the percept.

According to David Miall's summary, “Mark Johnson's book The Body in the Mind (1987) offers the claim that all thinking originates in bodily experience. A range of schemata formed during our early experience manipulating a physical world of surfaces, distances, and forces, lays the foundation of later, more abstract modes of thought". "Johnson insists that image schemata are not mental images, yet they are usually discussed as if they could be visualized in spatial terms". Speaking of time in terms of such spatial dimensions as "long" or "wide" would be an instance in point. In an attempt to show the difference between Mark Johnson's and their own approach to figurative language, Dou Kuiken and David Miall have argued that the process of defamiliarization, initiated by metaphor and other linguistic features, is characteristic of literary texts. Speaking of time as "wide" rather than "long" would be precisely such a defamiliarizing exercise. Such an exercise would force to our attention that "long time" is a dead spatial metaphor, that overfamiliarity may facilitate our functioning, but may also have devastating effects on the more important aspects of one's life. "The process of 
algebraization, the over-automatization of an object, permits the greatest economy of perceptive effort." says Shklovsky (1965: 12). But, on the other hand, "Habituation devours works, cloths, furniture, one's wife, and the fear of war". "The technique of art is to make the object 'unfamiliar', to make forms difficult, to increase the difficulty and length of perception". The defamiliarization of language may have far-reaching consequences of the ways we perceive the world. Consider the following paragraph

Morgenstern's playfulness [...] has a serious side to it. He is on record as claiming that man's basically unsatisfactory relationship to his fellows, his society and the world in general stems from his being imprisoned by language, which is a most unreliable, false and dangerous thing, and that one must "smash" language, destroy man's naive trust in this most familiar and unquestioned part of his life, before he can learn to think properly. Morgenstem's brilliantly witty games with words are thus, seen from this point of view, devious devices of alienation, and at their most radical succeed in producing in the reader a strange sensation-making one suddenly doubt one's comfortable relationship with language - not unlike the sense of disorientation and confusion associated with the grotesque (Thomson, 1972: 165).

A reader who reports to have perceived a witty effect in the phrase "wide, wide time" may have experienced it in this way, by defamiliarizing the spatial element in the dead metaphor. But, as I have pointed out above, some readers report a very different kind of effect. They feel as if they were wrapt in a low- differentiated texture of "time", or, as it were, "plunged" in it; as if the boundaries between self and not-self were suspended, while they (the readers) were "immersed" in "time". Some even report a faint tactile sensation all over the outer surface of their bodies. The change of adjectives has forced on these readers a shift in the kinds of space perception with the concomitant modes of information processing.

In my book On Metaphoring (Tsur, 1987: 155-165) I have devoted a long discussion to "Time" in poetry. I pointed out that "Time" had three different meanings: "Time may refer (a) to a sequence, (b) to the principle of that sequence, or (c) to a specific point in that sequence"; and that "Time" may have in poetry two kinds of character: the character of a concept, or of an emotionally charged mood or atmosphere.

Since both sequence (of time) and purposeful actions (of a superpersonal agent) are what we have called "linear", both time-as-a-sequence and time-as-a-generic-principle will tend to be perceived as compact concepts, intellectual abstractions. When time denotes a particular point in a sequence, part of a situation defined here-and-now, the abstraction may be related to spatial orientation, and perceived as a diffuse quality: a mood, an atmosphere. In such instances Time has a double function: it helps to define the immediate situation in time, and provides the abstraction that is to be perceived in it as a diffuse entity (Tsur, 1987: 157). 
When we speak of a "long road" or a "wide road", we are, in Wittgenstein's terms "aspect-switching"; or, rather, we are reorganizing information in our awareness. In the former case we are thinking of the road as having only one dimension, in the latter case as having two dimensions. When we speak of a "bumpy road", we are thinking of it as having three dimensions. The recoding of time experience into a spatial template may reorganize the experience in various ways, some of which are more, some of which are less accessible to conceptual language. Using the adjective "long" emphasizes the linear, sequential, continuous quality of time, as well as its directionality. The recoding of time experience into a spatial template by using the adjective "wide" shifts to a different experiencing of time, that is nonlinear, nonsequential, directionless, diffuse. This kind of experience is less accessible to conceptual language.

I have expressed above my reservations from the mediated association explanation of the correspondence between various modes of cognition. I have preferred Clark and Clark's cognitive explanation of markedness. "Children seem to attend more to the objects that 'have extent' than to those that 'lack extent' and this appears to explain why they typically learn the words for the positive ends of such dimensions first". This is the cognitive-developmental foundation of markedness. "Long" in this sense is less marked than "short"; but it is also less marked than "wide". The phrase "wide time" suggests that the phrase "long time" has been avoided, with all the implications suggested above; and above all, it effects a reorganization of the semantic information in consciousness, resulting in the loss of directionality. Thus, the markedness theory of antonymous adjectives can be much more illuminating of this piece of poetry (and many others) than the "mediated association" theory.

We have observed three possible levels in the correspondence of time with space. The first level can be epitomized as "DURATION IS LENGTH". At this level, the spatial metaphor is dead, and is of little literary or cognitive interest. When you ask "How long was the movie?", you hardly think of spatial relationships. At the second level we deautomatize the linguistic cliche, as suggested by Miall and Kuiken, generating some more satisfactory relationship to one's environment, enhancing and improving our awareness of reality - as suggested by Shklovsky or Morgenstern. This sudden shift is perceived as wit. At the third level, the change of adjectives effected a change of the modes of information-processing, conveying some kind of experience that is inacessible to ordinay conceptual language: we achieve the increased awareness of a diffuse, nonconceptual experience. The further away we move from the automatic application of the DURATION IS LENGTH paradigma, the more significant it becomes from the literary point of view.

The foregoing discussion may well indicate that I would hardly object to "preoccupation with spatial imagery", on the contrary rather. But I insist that the sophistication of the conceptual apparatus used to describe spatial imagery in language and poetry should match the sophistication of the phenomenon. 


\section{References}

Brown, Roger (1968) Words and Things. New York: The Free Press.

Burke, Kenneth (1962) A Grammar of Motives and A Rhetoric of Motives (in one volume). Cleveland \& New York: Meridian Books.

Clark, Herbert H. \& Eve V. Clark (1977) Psychology and Language: An Introduction to Psycholinguistics. New York: Harcourt, Brace \& Jovanovich.

Eco, Umberto (1976) A Theory of Semiotics. Bloomington: Indiana UP.

Freeman. Margaret H. (in press) "Poetry and the scope of metaphor: Toward a cognitive theory of literature". To appear in Metaphor \& Metonymy at the Crossroads. Ed. Antonio Barcelona, Mouton de Gruyter 1998.

Gardner, Howard (1982) Art, Mind, \& Brain. New York: Basic Books.

Gibbs, Ray (1997) "Conceptual Metaphors Underlying Conventional and Poetic Language”, paper presented at the "Cognitive Theories of Intertextuality" research workshop at the Porter Institute for Poetics and Semiotics, Tel Aviv University: December 30, 11997 January 1, 1998.

Johnson. M. (1987). The Body in the Mind: The Bodily Basis of Meaning, Imagination, and Reason. Chicago: Chicago University Press.

Kris, Ernst, and E. H. Gombrich (1965) "The Principles of Caricature", in Ernst Kris Psychoanalytic Explorations in Art. New York: Schocken.

Lakoff, George (1993) "The Contemporary Theory of Metaphor", in Andrew Ortony (ed.,) Thought and Metaphor. Cambridge: Cambridge UP (second ed.). 202-251.

Miall, David S. (1997) "The Body in Literature: Mark Johnson, Metaphor, and Feeling". Journal of Literary Semantics, 26 (3), 191-210.

Neisser, Ulric (1968 [ 1963'] "The Multiplicity of Thought”, in P. C. Wason and P. JohnsonLaird (eds.), Thinking and Reasoning. Harmondsworth: Penguin. 307-323.

Neisser, Ulric (1976) Cognition and Reality. San Francisco: Freeman.

Ornstein, Robert E. (1975) The Psychchology of Consciousness. Harmondsworth: Penguin. Polanyi, Michael (1967) The Tacit Dimension. Garden City, N.Y.: Anchor.

Shklovsky, Victor (1965) “Art as Technique”, in L. T. Lemon and M. J. Reis (eds.), Russsian Formalist Criticism. Lincoln: Nebraska UP. 3-24.

Smart, J. J. C. (1966) "Theory Construction”, in A. G. N. Flew (ed.), Logic and Language. Oxford: Blackwell. 222-242.

Thomson, Philip (1972) The Grotesque. London: Methuen.

Tsur, Reuven (1987). On Metaphoring. Jerusalem: Israel Science Publishers.

Tsur, Reuven (1992a). What Makes Sound Patterns Expressive - The Poetic Mode of Speech Perception.

Tsur, Reuven (1992b). Toward a Theory of Cognitive Poetics. Amsterdam: Elsevier (North Holland) Science Publishers.

Tsur, Reuven "Aspects of Cognitive Poetics".

Ullmann. Stephen (1957) "Panchronistic Tendencies in Synaesthesia", in The Principles of Semantics. Oxford: Blackwell. 266-289. 